\title{
Reducing Readmissions or Length of Stay-Which Is More Important?
}

\author{
Michael B. Rothberg, MD, MPH ${ }^{1 *}$, Natalie Lee, MD, MPH ${ }^{2}$
}

${ }^{1}$ Center for Value-Based Care Research, Cleveland Clinic, Cleveland, Ohio; ${ }^{2}$ Department of Medicine, Medicine Institute, Cleveland Clinic, Cleveland, Ohio.

Whether robbing banks or reducing healthcare spending, it makes sense to go where the money is. In the case of healthcare, $32 \%$ of spending goes to inpatient care, so hospitals represent a logical target for cost-reduction efforts. Because most hospital costs are fixed, there are basically 2 approaches to reducing spending - shorten length of stay or keep patients out of the hospital altogether. The government has tried both, using the power of financial incentives to spur adoption.

Faced with soaring hospital costs in the 1980s, Medicare introduced its prospective payment system, offering hospitals a fixed payment for each specific Diagnosis-Related Group. Hospitals responded by discharging patients sooner, with a resultant rise in admissions to skilled nursing facilities (SNFs) and rapid growth of the home care industry. Length of stay fell dramatically, dropping 9\% in 1984 alone. ${ }^{1}$ It continued to decline through the 1990s, falling by almost 20\% between 1993 and 2000. In the following decade, despite the rise of hospital medicine, the rate of decrease slowed to $0.2 \%$ per year. $^{2}$

Attention then turned to readmissions. In 2008, the Medicare Payment Advisory Committee proposed that hospitals with high risk-adjusted readmission rates receive lower payments, arguing that readmissions accounted for $\$ 15$ billion in Medicare spending and that many were preventable. Thus the Hospital Readmissions Reduction Program was born, introducing readmission penalties in 2012.

Numerous interventions emerged from government and nongovernment parties to reduce readmissions. Many used intensive transitional care programs focusing on early follow-up or medication safety, and some even went as far as providing transitional housing. ${ }^{3}$ Shortly after passage of the Affordable Care Act, readmission rates fell rapidly. Within a few years, however, the rate of decline slowed dramatically and may have reached a plateau. ${ }^{4}$ Many have argued that only a small proportion of readmissions are preventable and that there are more direct ways to promote improved discharge planning without diverting resources from other areas. ${ }^{5}$ It seems that readmissions may not be feasibly reduced much further.

\footnotetext{
*Address for correspondence and reprint requests: Michael B. Rothberg, MD, MPH, Center for Value-Based Care Research, Cleveland Clinic, 9500 Euclid Avenue, Cleveland, $\mathrm{OH}$ 44195. Telephone: 216-445-6600; Fax: 216-636-0046; E-mail: Rothbem@ccf.org
}

Received: May 2, 2017; Accepted: May 7, 2017

2017 Society of Hospital Medicine DOI 10.12788/jhm.2790
With the advent of accountable care organizations, health systems are now turning their focus to the small population of patients who consume a disproportionate share of healthcare dollars. Because the top $1 \%$ of patients-so-called super-utilizers-account for $21 \%$ of spending, efforts to reduce their utilization could produce outsized returns. ${ }^{6}$ Initial anecdotal reports described patients with complex physical, behavior, and social needs receiving fragmented care resulting in myriad expensive admissions. The response comprised teams of social workers and community health workers coupled with robust primary care, formulating individualized solutions. However, data supporting the effectiveness of this common-sense approach are lacking. In addition, our understanding of high-cost patients is evolving. For one thing, being a super-utilizer is often temporary, as just over one-quarter are still in that category a year later. ${ }^{7}$ Moreover, not all high-cost patients are frequently admitted. ${ }^{8}$

In this issue of The Journal of Hospital Medicine, Wick et al. ${ }^{9}$ provide additional insight into high utilizers of hospital services. The authors compare definitions of high utilizers based on cost, number of admissions, or cumulative length of stay over one year. Only 10 percent of high utilizers met all 3 definitions. The overlap between high utilizers by cost and length of stay was twice the overlap between high utilizers by number of admissions and either group. This finding is not surprising because hospitals have high fixed costs, so total cost tends to mirror length of stay.

The study was performed in Canada, and the overlap among these groups may be different in the US. The Canadian patients were hospitalized less frequently than their American counterparts, perhaps reflecting better access to primary care in the Canadian system. Regardless, Wick et al. ${ }^{9}$ add to the growing literature suggesting that the terms "high utilization" and "high cost" do not always describe the same population. This finding is important because strategies aimed at patients who are frequently admitted may not be effective for those who generate the highest costs. In trying to reduce overall costs, it may be time to revisit length of stay.

Given the long history of prospective payment in the US and the stagnation in length of stay over the past decade, it is reasonable to wonder whether further reductions are possible. In the study by Wick et al., ${ }^{9}$ patients with longer lengths of stay were discharged to long-term care facilities. This observation is consistent with others' reports. Studies of delays in care show that at least $10 \%$ of all hospital days can be attributed to delays in discharge, especially to SNFs. In the most recent study, $11 \%$ of hospital days were deemed unnecessary by hospitalists, with one-third of those delays 
due to lack of availability at an extended care facility. ${ }^{10}$ Six years earlier, Carey et al. found that $13.5 \%$ of inpatient days were unnecessary, with more than $60 \%$ of delays attributable to waiting for discharge to a SNF.11

How, then, might we curtail unnecessary waiting, and whose job is it to solve the problem? The prospective payment system should reward hospitals for eliminating waiting-particularly those hospitals operating at capacity, for which the opportunity costs of occupied beds are most acute. Hospitalists, per se, have no incentive to discharge patients who are waiting; these patients are easy to round on, rarely have emergencies, and generate daily bills. Even when hospitalists are employed by the hospital and incentives for both are aligned, hospitalists may still be powerless to discharge waiting patients, summon busy consultants, or create extra slots in the endoscopy suite.

The move to value at the system level may offer hope. As health systems become responsible for the total cost of care, their focus must shift from the individual areas where care is provided to the transitions of care between treatment areas. It is in these transitions that US healthcare has failed most spectacularly, and consequently, it is where the greatest opportunity lies.

To date, most discharge interventions have focused on communication, with a goal of improving patient safety and, to a lesser extent, preventing readmissions. Partnering with SNFs can reduce the rate of readmissions, ${ }^{12}$ but for the most part, the incentives for hospitals and post-acute care facilities remain misaligned. Because post-acute care facilities are paid per diem, they have little incentive to reduce patients' stays or to admit new patients, who are more expensive to care for than existing ones. Physicians round on SNF patients infrequently and have no incentive to discharge patients, exacerbating the problem. Because post-acute care represents a growing proportion of costs for both medical and surgical patients, health systems will need to either have their own facilities or enter into contracts that align the incentives.

What can hospitalists do? As the predominant coordinators of hospitalized patients' care both for medical and surgical teams, hospitalists meaningfully impact readmissions and lengths of stay through the care they provide. ${ }^{13}$ More important, as their roles in optimizing hospital throughput ${ }^{14}$ continue to expand, hospitalists are perhaps best positioned to observe a diverse range of inefficiencies and inadequacies in inpatient practice and translate those observations into new systems of care. Through thoughtful participation in hospital operations, administration, and health services research, hospitalists hold the key to improving the value of care we provide.

Disclosure: Nothing to report.

\section{References}

1. Davis C, Rhodes DJ. The impact of DRGs on the cost and quality of health care in the United States. Health Policy. 1988;9(2):117-131.

2. Healthcare Cost and Utilization Project (HCUP). Statistical Brief \#180. Overview of Hospital Stays in the United States, 2012. Available at: https:/www. hcup-us.ahrq.gov/reports/statbriefs/sb180-Hospitalizations-United-States-2012. pdf. Accessed July 17, 2017.

3. Kansagara D, Chiovaro JC, Kagen D, et al. So many options, where do we start? An overview of the care transitions literature. J Hosp Med. 2016;11(3):221-230.

4. Zuckerman RB, Sheingold SH, Orav EJ, Ruhter J, Epstein AM. Readmissions, observation, and the Hospital Readmissions Reduction Program. N Engl J Med. 2016;374(16):1543-1551.

5. Joynt KE, Jha AK. Thirty-day readmissions-truth and consequences. N Engl J Med. 2012;366(15):1366-1369.

6. Stanton MW, Rutherford MK. Research in Action: The high concentration of U.S. health care expenditures. Agency for Healthcare Research and Quality. Available at: https://meps.ahrq.gov/data_files/publications/ra19/ra19.pdf. Accessed July $17,2017$.

7. Johnson TL, Rinehart DJ, Durfee J, et al. For many patients who use large amounts of health care services, the need is intense yet temporary. Health Aff (Millwood). 2015;34(8):1312-1319.

8. Lee NS, Whitman N, Vakharia N, PhD GB, Rothberg MB. High-cost patients: hot-spotters don't explain the half of it. J Gen Intern Med. 2017;32(1):28-34.

9. Wick JP, Hemmelgarn BR, Manns BJ, et al. Comparison of methods to define high use of inpatient services using population-based data. J Hosp Med. 2017;12(8):596602 .

10. Kim CS, Hart AL, Paretti RF, et al. Excess hospitalization days in an academic medical center: perceptions of hospitalists and discharge planners. Am J Manag Care. 2011;17(2):e34-42.

11. Carey MR, Sheth H, Braithwaite RS. A prospective study of reasons for prolonged hospitalizations on a general medicine teaching service. J Gen Intern Med. 2005;20(2):108-115.

12. Kim LD, Kou L, Hu B, Gorodeski EZ, Rothberg MB. Impact of a connected care model on 30-day readmission rates from skilled nursing facilities. J Hosp Med. 2017;12(4):238-244.

13. Southern WN, Berger MA, Bellin EY, Hailpern SM, Arnsten JH. Hospitalist care and length of stay in patients requiring complex discharge planning and close clinical monitoring. Arch Intern Med. 2007;167(17):1869-1874.

14. Chadaga SR, Maher MP, Maller N, et al. Evolving practice of hospital medicine and its impact on hospital throughput and efficiencies. J Hosp Med. 2012;7(8):649-654. 